\title{
Design of 3-Bit Digital RF Phase Shifter for Wireless Communication
}

\author{
B.Nataraj, K.R.Prabha
}

\begin{abstract}
In this paper, a 3-bit digital phase shifter based on switched transmission line technique using coplanar waveguide is proposed. The design has the resonant frequency of $10 \mathrm{GHz}$ which can be used in wireless communication applictaions. Recent developments in radio frequency components development has raised as a significant way for constructing low loss phase shifters. MEMS phase shifters whose insertion loss is low and high isolation uses minimum power. This helps to bring low cost and light weighted phased array antennas. The transmission line length and wavelength decides the characteristics of phase shift. The phase shifter design consists of coplanar waveguides having center conductor width of 100 $\mathrm{\mu m}$ and the gap of $14 \mu \mathrm{m}$ on a FR-4 epoxy substrate with thickness of $1.6 \mathrm{~mm}$. The design is simulated using ADS to yield phase shift of $45^{\circ}, 90^{\circ}$ and $180^{\circ}$. The benefits of digital phase shifters include achieving flat phase over a wide bandwidth as well as having higher power handling and linearity with uniform performance. The phase shifters are used in different fields which includes microwave devices, feeder of radio system, phased array antenna, coherent radio system, etc.
\end{abstract}

Index Terms: Radio Frequency, Microelectromechanical Systems, Coplanar Waveguide, phase shifter.

\section{INTRODUCTION}

Phase shifters are used in RF and microwave communication, radar and measurement systems and also benefits applications in phased array antenna and radio communication. In a RC network, the output can lead or lag the incoming signal by $90^{\circ}$ in a phase shifter. Analog and digital phase shifters are the different kinds of phase shifters. Analog phase shifters are controlled by voltage level and it is varied continuously. The analog type of phase shifters are usually narrowband and its wide frequency ranges upto 10 GHz. The type of phase shifters used here is digital phase shifters. Variation of time delay or discrete phase shift is given by digital phase shifter. More number of digital phase shifters are used which is an essential component in satellite systems. The losses and noises can be eliminated by using digital phase shifters. Based on PIN diode assembly, the

Revised Manuscript Received on 30 July 2019.

* Correspondence Author

B.Nataraj*, Associate Professor,Department of Electronics and Communication Engineering, Sri Ramakrishna Engineering College, Coimbatore.

K.R.Prabha, Assistant Professor, Department of Electronics and Communication Engineering, Sri Ramakrishna Engineering College, Coimbatore

(C) The Authors. Published by Blue Eyes Intelligence Engineering and Sciences Publication (BEIESP). This is an open access article under the CC-BY-NC-ND license http://creativecommons.org/licenses/by-nc-nd/4.0/

digital phase shifters are modeled. The phase angle of a RF signal is changed by a passive microwave element, RF phase shifters. Loaded line phase shifter and switched line phase shifter are different kinds of MEMS phase shifters. A transmission line loaded with two different impedances values selected by two switches is loaded line phase shifter whereas by using switches, the input signal is switched between lines of different electrical lengths to get different phase shifts is switched line phase shifters. It has less power consumption than loaded line. The switched line phase shifter is one of the easiest ways to implement the design and is fabricated on PCB by its own.

\section{TRANSMISSION LINE}

An electrical signal transmitted over a pair of electrical conductors from one range to another is referred to as transmission line. In order to transmit high radio frequency (RF) signals and acoustic signals, transmission lines are used. Planar transmission lines are the most commonly used line at RF range. Planar lines are conductors or strip lines which is flat and ribbon shaped. They are interconnectors used on printed circuits and integrated circuits due to its fitting in the manufacturing units. They are also called as dielectric strips. The types of planar transmission lines most commonly used at $\mathrm{RF}$ range are strip line, microstrip line and coplanar waveguide. The first ever found transmission line is strip lines which has strip conductor centered between two parallel ground planes with two equal slabs of a dielectric, ferrite or semiconductor medium separating the centre conductor from the ground plane. The medium used here is solid material and the air is used as a actual dielectric. It has good electromagnetic shielding and low attenuation loss which is suitable for high quality factor and low interference applications. Microstrip lines, showh in figure 1 have single conductor trace on one side and single ground plane on the other side. It is open structure and it can be easy for fabricated and though it offers low electrical performance, attenuation loss and power handling are compromised.

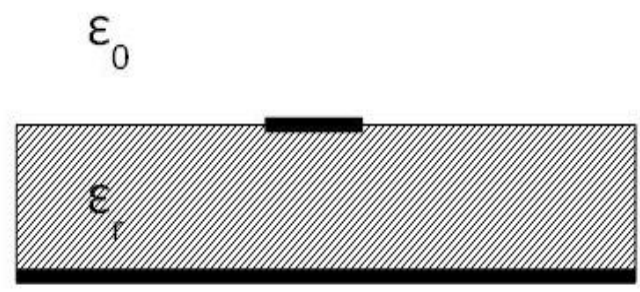

(a) 


\section{Design of 3-Bit Digital RF Phase Shifter for Wireless Communication}

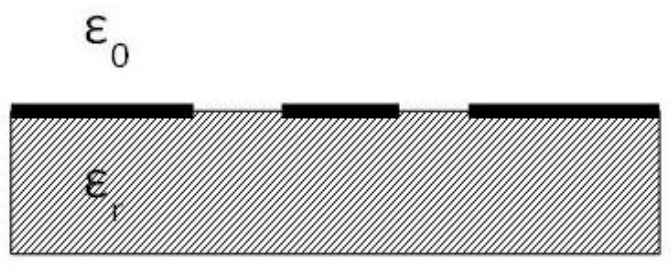

(b)

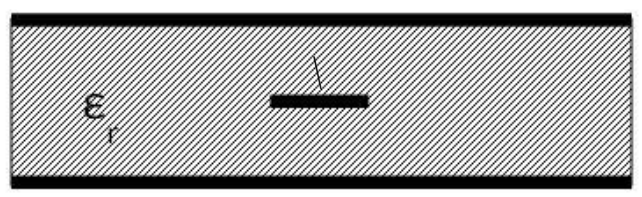

(c)

Figure 1. (a) Stripline, (b) Microstrip Line, (c) Coplanar Waveguide

The electromagnetic waveguides are carried by coplanar waveguide (CPW) both exist partly in dielectric substrate and air. The center conductor and ground planes are situated on the substrate surface. The transmission line which is mostly suitable for high frequency applications is CPW. Coplanar waveguides are uniplanar in solid state quantum. The advantages that includes in CPW are dispersion is low, realization of short circuit ends are very simple, easy for attaching shunt and series circuit elements and undesirable parasitic inductances are introduced, since there is no need for via holes and also the performances are limited at high frequencies. CPW promotes a quasi-TEM dominant. Nowadays, high power electronic applications can be operated at frequencies of $100 \mathrm{GHz}$ and beyond the frequency ranges. At such frequencies, for device are connected and signal is distributed through transmission lines. Coplanar waveguide are used for fabricating thick substrates has it has supporting wave propagation is located on the same plane. For signal characterization and MMICs coplanar waveguide has been used.

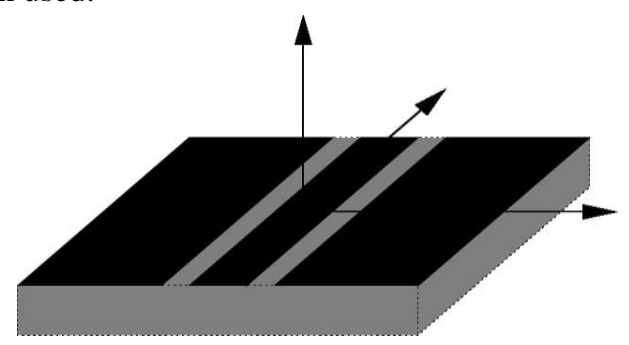

Figure 2. Coplanar Waveguide

\section{PHASE SHIFTER DESIGN}

Switched transmission line technique is used for designing phase shifters in this paper. The phase shifters of different degrees such as $45^{\circ}, 90^{\circ}$ and $180^{\circ}$ are designed at $10 \mathrm{GHz}$ operating frequency which is useful for wireless communication. The design consists of FR-4 substrate with thickness of $1.6 \mathrm{~mm}$, a dielectric constant of 4.4 and loss tangent is 0.002 . The characteristic impedance of the coplanar transmission line is $50 \Omega$. The thickness of the copper conductor material is given as $17 \mu \mathrm{m}$. The design aims to provide better and acuurate phase shifts with very low insertion loss and better return loss for the 3 different phase shifts. The guided wavelength of the transmission line is given by

$$
\lambda_{g}=\frac{\lambda}{\sqrt{\varepsilon_{\text {eff }}}}
$$

where $\lambda$ is the free space wavelength given as $\mathrm{c} / \mathrm{f}$ where $\mathrm{c}$ is the free space velocity ( $3 \times 108 \mathrm{~m} / \mathrm{s}$ ) and $\mathrm{f}$ is the operating frequency, eeff is the effective dielectric constant which is given by

$$
\varepsilon_{\text {eff }} \approx \frac{\varepsilon_{r}+1}{2}
$$

The 3-bit phase shifts intended for this paper has the line lengths of design of $2304 \mu \mathrm{m}$ for a $45^{\circ}$ phase shift, $4300 \mu \mathrm{m}$ for $90^{\circ}$ phase shift and $9000 \mu \mathrm{m}$ for $180^{\circ}$ phase shift of a CPW transmission line center conductor width (W) is $100 \mu \mathrm{m}$ and the gap (G) is $14 \mu \mathrm{m}$ fabricated on a FR-4 substrate. The layouts of each bit phase shifter representing $45^{\circ}, 90^{\circ}$ and $180^{\circ}$ are shown in figure 3,4 and 5 respectively.

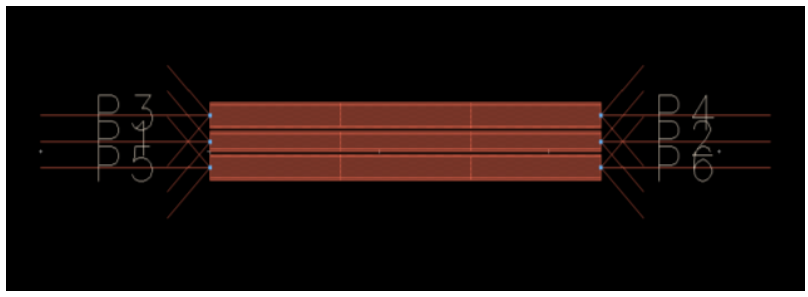

Figure 3. Schematic diagram of $45^{\circ}$ phase shifter

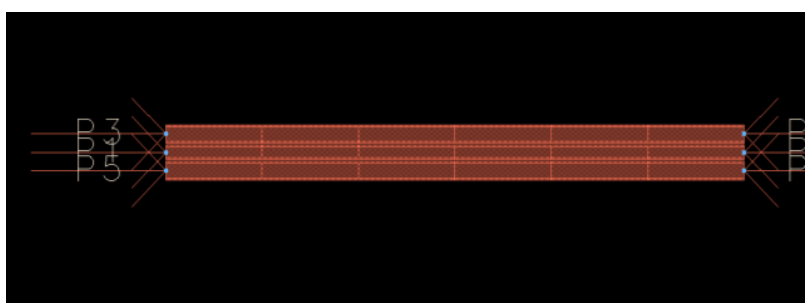

Figure 4. Schematic diagram of $90^{\circ}$ phase shifter

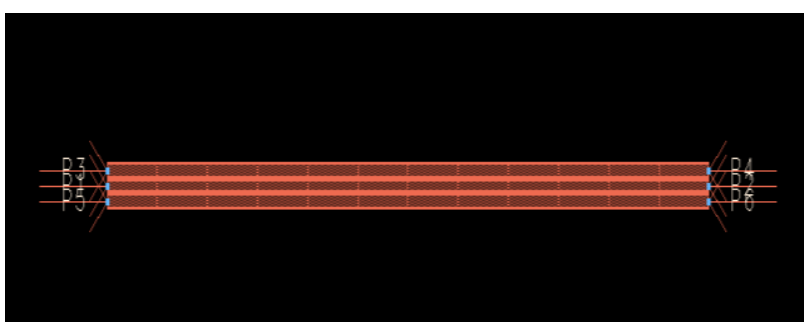

Figure 5. Schematic diagram of $180^{\circ}$ phase shifter

Published By: 


\section{SIMULATION RESULTS}

The design of various bit phase shifters are simulated using Advanced Design System (ADS) software. The change in phase shift and best quality performance than the conventional RF phase shifter in terms of low insertion loss are due to the characteristic impedance change and the structure change. The simulated results of $45^{\circ}, 90^{\circ}$ and $180^{\circ}$ phase shifters using ADS software is shown in figure $6-14$. The digital phase shifter designed at $10 \mathrm{GHz}$ operating frequency provides better return loss ( $\mathrm{S} 11 \mathrm{~dB})$ for $45^{\circ}$ phase shifter design is -21.864 $\mathrm{dB}$ Shown in figure 6 and insertion loss (S12 dB) below $-0.08 \mathrm{~dB}$ as shown in figure7. Figure 8 shows the phase shift (S12 phase) of $45.55^{\circ}$ at $10 \mathrm{GHz}$ which agrees with the required design of $45^{\circ}$. The $90^{\circ}$ phase shifter design provides return loss $(\mathrm{S} 11 \mathrm{~dB})$ of $-18.41 \mathrm{~dB}$ and insertion loss (S12 dB) below $-0.167 \mathrm{~dB}$ as shown in figure 9 and 10 . The phase shift obtained for $90^{\circ}$ bit design which is $84.76^{\circ}$ which is shown in figure 11 with a phase error of $5.24^{\circ}$. The $180^{\circ}$ digital phase shifter design provides better return loss (S11 dB) of $-36.56 \mathrm{~dB}$ and insertion loss (S12 dB) below $-0.22 \mathrm{~dB}$ as shown in figure 12 and 13 . The phase shift obtained for $180^{\circ}$ bit which is $177.10^{\circ}$ which is shown in figure 14 with a phase error of $2.89^{\circ}$.

$$
\begin{aligned}
& \mathrm{m} 1 \\
& \text { freq=10.00GHz } \\
& \mathrm{dB}(\mathrm{S}(1,1))=-21.864
\end{aligned}
$$

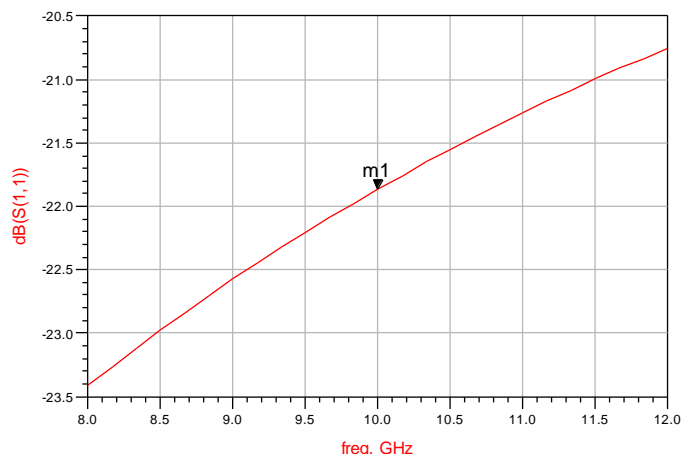

Figure 6. Return loss for $45^{\circ}$ design

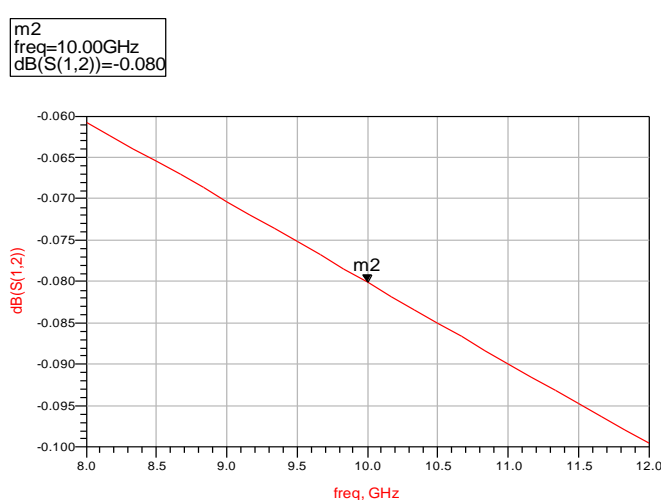

Figure 7. Insertion loss for $45^{\circ}$ design

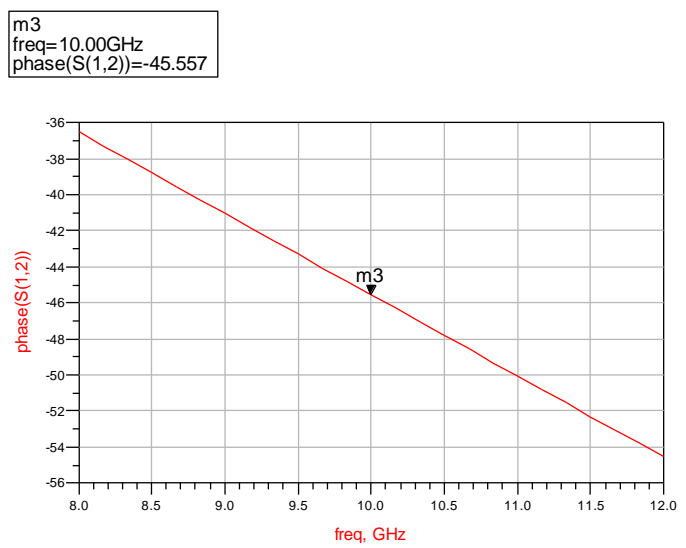

Figure 8. Phase shift for $45^{\circ}$ design$$
\mathrm{m} 1
$$$$
\text { freq }=10.00 \mathrm{GHz}
$$$$
\mathrm{dB}(\mathrm{S}(1,1))=-18.411
$$

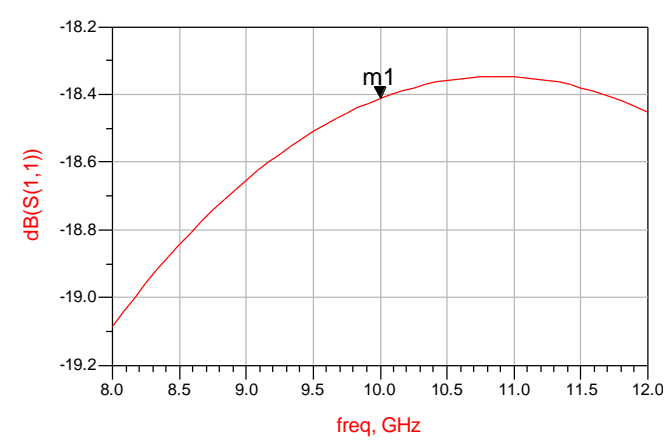

Figure 9. Return loss for $90^{\circ}$ design

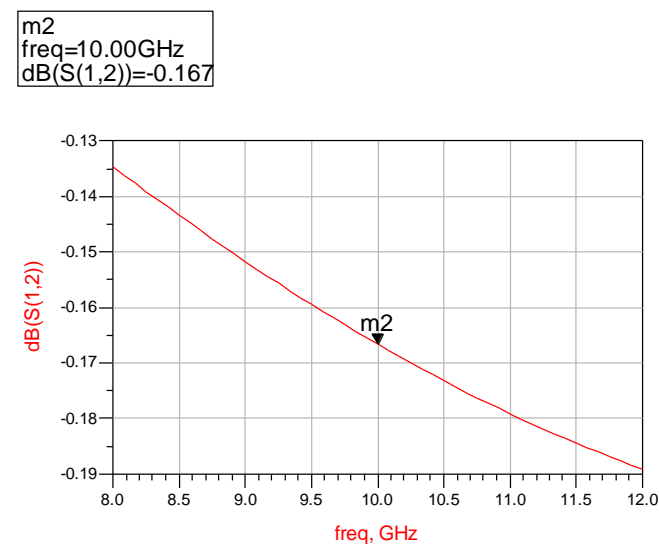

Figure 10. Insertion loss for $90^{\circ}$ design

$$
\mathrm{m} 3
$$

freq $=10.00 \mathrm{GHz}$

phase $(\mathrm{S}(1,2))=-84.764$

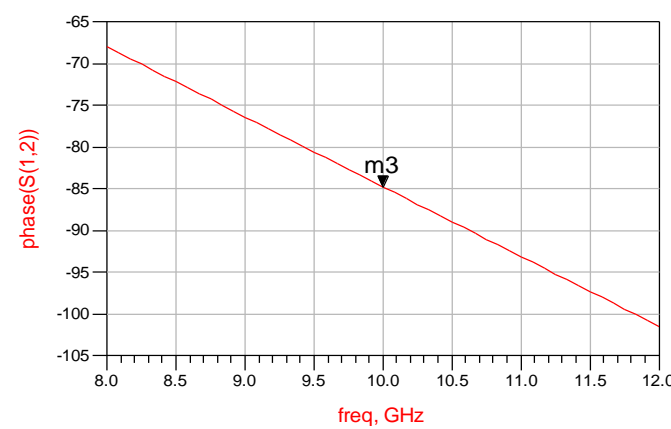

Figure 11. Phase shift for $90^{\circ}$ design 


\section{Design of 3-Bit Digital RF Phase Shifter for Wireless Communication}

$\mathrm{m} 1$

req $=10.00 \mathrm{GHz}$

$\mathrm{dB}(\mathrm{S}(1,1))=-36.560$

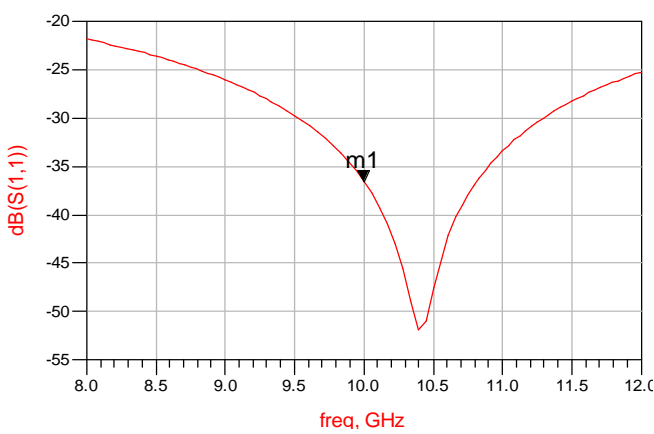

Figure 12. Return loss for $180^{\circ}$ design
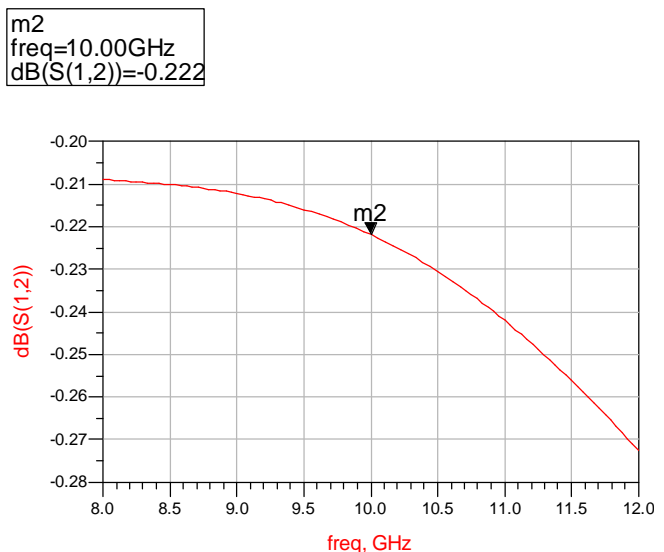

Figure 13. Insertion loss for $180^{\circ}$ design
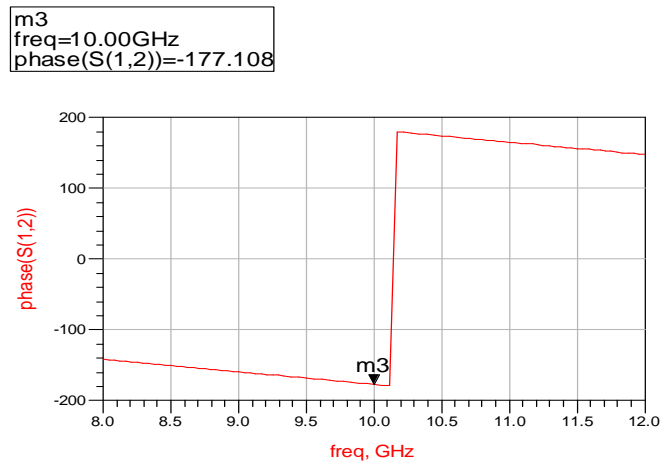

Figure 14. Phase shift for $180^{\circ}$ design

\section{CONCLUSION}

The 3-bit digital RF phase shifter developed based on switched transmission line is designed for $10 \mathrm{GHz}$ operating frequency. The proposed design shows the performance with maximum phase shift such as $45.55^{\circ}, 84.76^{\circ}$ and $177.10^{\circ}$ for $45^{\circ}, 90^{\circ}, 180^{\circ}$ respectively. The phase error is less than $5.3^{\circ}$. Therefore, a maximum phase shift is obtained with minimum wavelength. With these techniques, we could achieve higher resolutions, larger phase shift per unit length and low loss phase shifters. The future work is to increase the isolation, reduce the insertion loss and mainly to increase the phase shift per unit length. This can be used for satellite, wireless communications and wideband frequency applications and it is also used in phased array antennas.

\section{REFERENCES}

1. B. Nataraj, K.R. Prabha, S. Surya Sri, G. Suguna and K.A. Swathi, 2018, "Design of RF MEMS Phase Shifter using Capacitive Shunt Switch", International Journal of Pure and Applied Mathematics, Vol. 119, No. 10, pp. 1053-1066.

2. Kevin D. Leedy, Richard E. Strawser, 2007, "Thin - Film Encapsulated RFMEMS switches", IEEE Journal of MEMS, vol. 16, no. 2.

3. Gabriel M. Rebeiz, 2007, "RF MEMS Theory, Design and Technology", $1^{\text {st }}$ Ed., Wiley \& Sons Inc.

4. S.Dey, S.K.Koul , A.K.Poddar and U.L.Rohde, 2017 "Ku to V-band 4-bit MEMS phase shifter bank using high isolation SP4T switches and DMTL structures" Journal of Micromech. Microeng., vol.27, no.10, p.105010.

5. S.K.Koul , S.Dey , A.K.Poddar , and U.L.Rohde, 2016, "Ka-band reliable and compact 3-bit true-time delay phase shifter using MEMS single pole-eight-throw switching networks", Journal of Micromech. Microeng ., vol.26, no.10,p.104002.

6. [6] Thermpon Ativanichayaphong, Ying Cai and J.C. Chiao, 2005, "Design and Modeling of Distributed RF MEMS Phase Shifters", VI International Conference on Micro Electro Mechanical Systems, 2005.

7. Christos G Christodoulou, "RF MEMS and its Applications to Microwave Systems", IEEE Antennas and Wireless Communications, 2003.

8. MonFernandez-Bolanos Badia, Elizabeth Buitrago, Adrian Mihai Ionesco, 2012, "RF MEMS Shunt capacitive switches using AIN", IEEE Journal of MEMS, vol. 21, issue 5.

9. Rainee N. Simon, 2007, "Coplanar Waveguide Circuits components and systems”, IEEE Transaction on Microwave Theory and Techniques, vol. 44, issue 245.

10. Wen, C. P, 1969, “Coplanar waveguide: A surface strip trans- mission line suitable for nonreciprocal gyromagnetic device applications", IEEE Transactions on Microwave Theory and Techniques, vol. 17, pp 1087-1090.

11. A. Malczewski, S. Eshelman, B. Pillans, J.Ehmke and C.L. Goldsmith, 1999, "X-band RF MEMS phase shifters for phased array applications", IEEE Microwave Guided Wave Letters, vol. 9, pp.517-519.

12. B.Nataraj, K.Porkumaran, 2012, "Investigation of RF MEMS phase shifter using Tapered Coplanar Waveguide", European Journal of Scientific Research, Volume 69, no.3,pp.360-369.

13. Vijay K. Vardhan, K.J Vinoy, K.A Bose, 2003, "RF MEMS and their applications", Wiley

14. Topalli, K., Unlu, M., Civi, O.A., Demir, S., Koc, S. and Akin, T.,2006 "A monolithic phased array using 3-bit DMTL RF MEMS phase shifters", IEEE Proceedings of Antennas and Propagation Society International Symposium, Albuquerque, New Maxico, United State, July 9-14, 2006, pp.517-520.

\section{AUTHORS PROFILE}

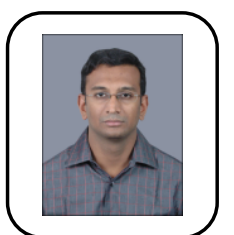

Dr.B.Nataraj completed his Ph.D in Information and Communication Engineering from Anna University, Chennai in 2015. He received his M.E. in Communication Systems from Thiagarajar College of Engineering, Madurai in 2004 and B.E. in Electronics and Communication Engineering from Thiagarajar College of Engineering, Madurai in 2002. He has11.5 years of teaching experience. His research interest includes RF / Microwave and RF MEMS Devices. He has published more than 16 research papers in national and international journals and 13 papers in national/international conferences. He was the incharge of Signal Processing Laboratory and received a fund of Rs. 15 Lakhs towards MODROB scheme for modernizing Signal Processing and VLSI lab from All India Council of Technical Education, New Delhi. He had addressed several Guest Lectures in the area of RF Transmission Lines, RF MEMS, Microsensors, Signals and Systems and Digital Signal Processing. He has chaired sessions for various national conferences and is a reviewer member for many national and international journals. He is a member in professional societies like ISTE and IAENG.

\section{Published By:}

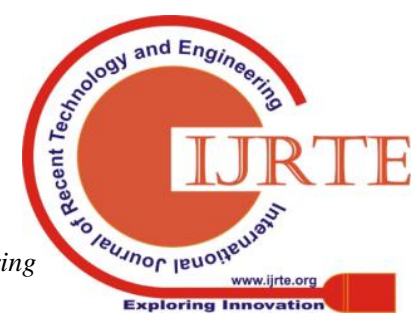




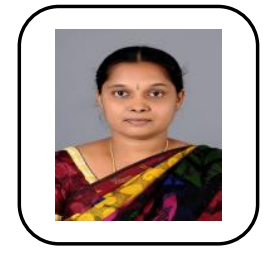

K.R.Prabha received the B.E. degree in Electronics and Communication Engineering from Vivekanandha College of Engineering for Women in 2005 and M.E. Communication Systems from Mahendhra Engineering College in 2009. Currently she is pursuing her $\mathrm{PhD}$ in Digital Image Processing. In 2010, she joined department of Electronics and Communication Engineering, Sri Ramakrishna Engineering College, where she is an Assistant Professor. Her areas of interest are Electronic Circuits, Digital Image Processing, Microwave Engineering and Wireless Communication. She is member in professional societies like ISTE. 